\title{
Weakening of the mid-latitude summer nighttime anomaly during geomagnetic storms
}

\author{
Huixin Liu $^{1,2}$ and Mamoru Yamamoto ${ }^{3}$ \\ ${ }^{1}$ Earth and Planetary Science Division, Kyushu University, Japan \\ ${ }^{2}$ Space Environment Research Center, Kyushu University, Japan \\ ${ }^{3}$ Research Institute for Sustainable Humanosphere, Kyoto University, Japan
}

(Received July 16, 2010; Revised October 27, 2010; Accepted November 21, 2010; Online published June 14, 2011)

\begin{abstract}
This brief report presents geomagnetic storm effects on the formation and characteristics of the midlatitude summer nighttime anomaly (MSNA). This anomaly is a phenomenon where the diurnal variation of the plasma density maximizes at night instead of day. Under disturbed geomagnetic conditions, the MSNA is found to have smaller spatial coverage, lower magnitude of the reversed diurnal cycle, and shorter duration of the nighttime enhancement. All these features demonstrate a weakening of the MSNA. In addition, the nighttime maximum tends to occur at earlier local time. These effects can be reasonably understood in the frame of storm-induced equatorward wind and the molecular-rich air it carries along with. For instance, the shrink of the spatial coverage is essentially a dominant effect of the molecular-rich air, which tends to deplete the plasma significantly on the poleward edge of the MSNA region. On the other hand, the smaller magnitude and the shorter duration seem to be mainly caused by the storm-induced equatorward wind. Storm effects presented here add further evidence to the pivot role of effective neutral wind in the formation of MSNA.
\end{abstract}

Key words: Middle-latitude ionosphere, summer night anomaly, neutral wind, magnetic storms.

\section{Introduction}

The ionosphere at middle latitudes exhibits an unique anomaly, where the electron density $\left(N_{\mathrm{e}}\right)$ maximizes at night instead of noon, leading to a phase reversal of the normal diurnal cycle. This phenomenon of reversed diurnal cycle occurs in three distinct regions on the globe in local summer. They are the East Asian (EA) region centered around $\left(53^{\circ} \mathrm{N}, 150^{\circ} \mathrm{E}\right)$, the Northern Atlantic (NA) region centered around $\left(45^{\circ} \mathrm{N}, 50^{\circ} \mathrm{W}\right)$ and the South Pacific (SP) region centered around $\left(60^{\circ} \mathrm{S}, 110^{\circ} \mathrm{W}\right)$ (Liu et al., 2010). The SP region in the southern hemisphere has long been recognized and referred to as the "Weddell Sea Anomaly" (WSA) since 1950s (Bellchambers and Piggott, 1958; Dungey, 1961; Horvath and Essex, 2003; Horvath, 2006; Jee et al., 2009). The EA and NA in the northern hemisphere are revealed by recent satellite and ground observations (Liu et al., 2007, 2010; Lin et al., 2009; Thampi et al., 2009). The midlatitude summer nighttime anomaly (MSNA) is now generally used to refer to this phenomenon in both northern and southern hemispheres.

The cause for this anomaly involves several inter-playing physical processes. Among these, the neutral wind component in the geomagnetic meridian, combined with the later sunset in summer, play dominant roles as comprehensively discussed in He et al. (2009) and Liu et al. (2010). At middle latitudes, this meridional component (in geomagnetic

Copyright (C) The Society of Geomagnetism and Earth, Planetary and Space Sciences (SGEPSS); The Seismological Society of Japan; The Volcanological Society of Japan; The Geodetic Society of Japan; The Japanese Society for Planetary Sciences; TERRAPUB.

doi:10.5047/eps.2010.11.012 frame) lifts the ionosphere at night and pushes it down during day. Since the chemical recombination decreases with altitude, this vertical movement tends to enhance the nighttime plasma but deplete the day-time plasma. This wind effect varies significantly with longitude, due to the variation of magnetic declination and inclination. It is strongest at three longitudes near $90^{\circ} \mathrm{W}, 40^{\circ} \mathrm{W}$, and $150^{\circ} \mathrm{E}$. Variation of this wind component has direct effect on the formation and characteristic of MSNA.

Up till now, investigation of this phenomemon has been limited to geomagnetically quiet conditions. However, the neutral wind system is known to be significantly affected by magnetosphere energy input during geomagnetic storms. Strong horizontal wind and upwelling are produced by Joule heating in the auroral region. This storm-induced wind carries molecular-rich air from the high to middle latitudes, which can dramatically increase the recombination rates (Prölss, 1981, 1993; Fuller-Rowell et al., 1994). At the same time, the mechanical effects of the wind which moves the plasma in the vertical direction continues to operate during storms. The dominance of these two effects depends on local time, season, and duration of the main phase of the storm (see e.g. Balan et al., 2010). Thus, we anticipate geomagnetic storms to have a clear influence on characteristic of MSNA. This speculation is examined in this brief report using satellite observations.

\section{Data}

To facilitate easy comparison with results under quiet conditions $\left(K_{\mathrm{p}} \leq 3\right)$ reported in Liu et al. (2010), we make use of the same in-situ measurements of electron density $N_{\mathrm{e}}$ 

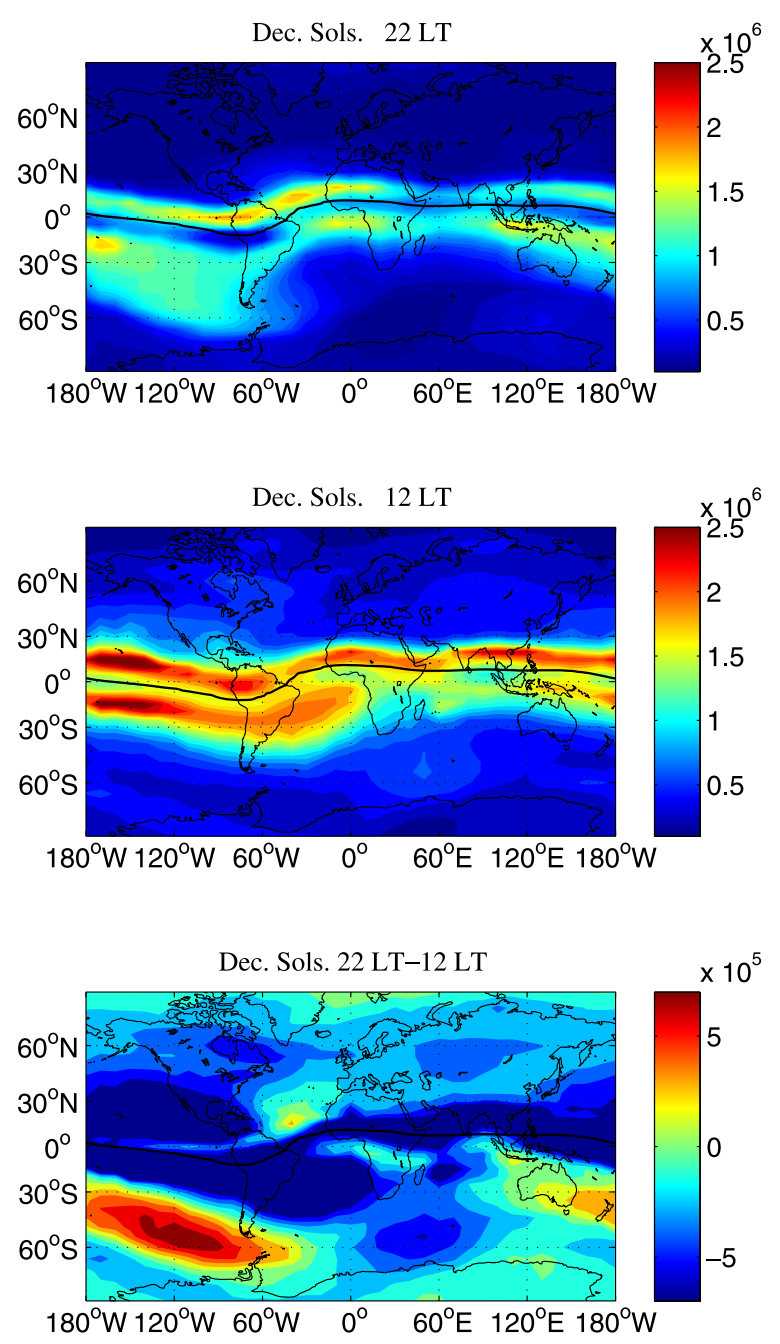
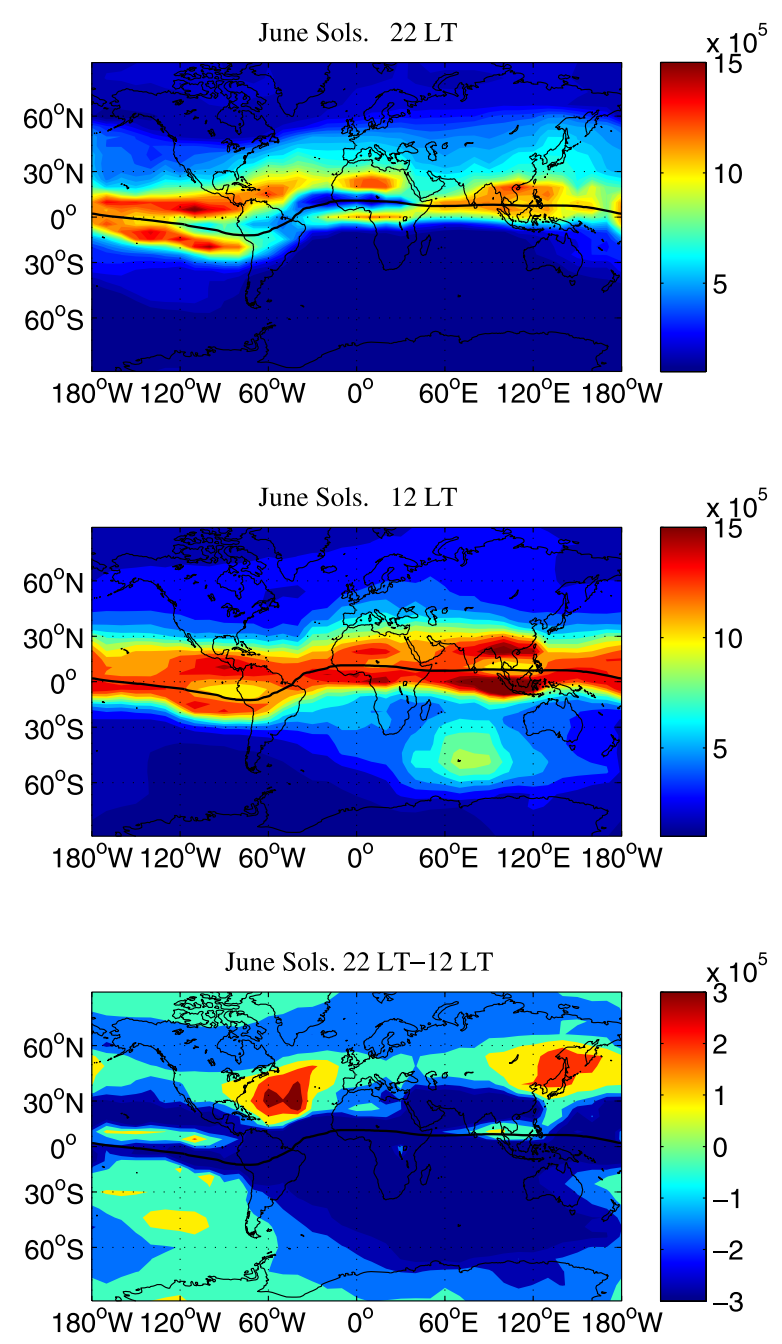

Fig. 1. Geographical distribution of $N_{\mathrm{e}}$ at $400 \mathrm{~km}$ at night (22 LT), day (12 LT), and the difference between them under disturbed conditions at moderate solar flux levels $\left(F_{10.7}=130\right)$. The left column is for December solstice and the right one for June solstice. Note different color scales are used to clearly show the relevant patterns in each figure.

from the Planar Langmiur Probe (PLP) on board CHAMP satellite for disturbed conditions $\left(K_{\mathrm{p}} \geq 4\right)$. Data period covers from January 1, 2001 to December 31, 2006. The data are subdivided into two groups, with one representing solar maximum $(\mathrm{SMAX})\left(F_{10.7} \approx 160\right)$ and one representing solar minimum $(\mathrm{SMIN})\left(F_{10.7} \approx 90\right)$. Furthermore, a normalization of the data to a common altitude of $400 \mathrm{~km}$ has been applied to possibly exclude variations induced by the orbit decay. These data period and analysis procedure are identical to that for quiet conditions described in Liu et al. (2010). CHAMP is in a near-circular orbit with an inclination of $87.3^{\circ}$ and an initial height of about $450 \mathrm{~km}$ at launch in July 2000. Its orbital plane precesses through all local times every four months and through all longitudes at a fixed local time every 24 hours.

\section{Results}

\subsection{Distribution of the anomaly diurnal cycle regions}

Geographical distributions of $N_{\mathrm{e}}$ at $400 \mathrm{~km}$ in June and December under disturbed conditions are depicted in Fig. 1 to illustrate the diurnal anomaly regions at moderate solar flux levels $\left(F_{10.7} \approx 130\right)$. Nighttime $N_{\mathrm{e}}$ patterns represented by that at 22 LT is shown in the top panels, while noontime patterns around 12 LT are shown in the middle panels. Density differences between day and night ( $\Delta N_{\mathrm{e}}=N_{\text {enight }}-N_{\text {eday }}$ ) are given in the bottom panels. The numbers of satellite tracks used for obtaining the December maps are 415 for 22 LT and 378 for 12 LT, respectively. And for the June maps, these numbers are 306 and 321. The rather close numbers for $22 \mathrm{LT}$ and $12 \mathrm{LT}$ exclude large errors due to imbalanced sampling in the result.

As seen in the bottom panels, three distinct regions with positive $\Delta N_{\mathrm{e}}$ exist, signaling regions of reversed diurnal cycle or MSNA. It centers near $\left(55^{\circ} \mathrm{S}, 120^{\circ} \mathrm{W}\right)$ in the South Pacific (SP), $\left(48^{\circ} \mathrm{N}, 130^{\circ} \mathrm{E}\right)$ in East Asia sector (EA) and $\left(35^{\circ} \mathrm{N}, 50^{\circ} \mathrm{W}\right)$ in the North Atlantic (NA). In comparison to quiet-time distributions dipicted in figure 1 of Liu et al. (2010), three features can be recognized. First, the anomaly regions shrink. For instance, the SP region covers from about $170^{\circ} \mathrm{E}-50^{\circ} \mathrm{W}, 30^{\circ} \mathrm{S}-70^{\circ} \mathrm{S}$, an area about $20 \%$ smaller than that under quiet conditions. Second, the anomaly regions shift equatorward for about $5^{\circ}-10^{\circ}$ to their quiet-time locations. For instance, the NA region was centered at $35^{\circ} \mathrm{N}$ instead of $45^{\circ} \mathrm{N}$ under quiet conditions. Third, the magnitude of the anomaly (the nighttime-to-noontime ratio) becomes smaller (this will be seen more clearly in the follow- 

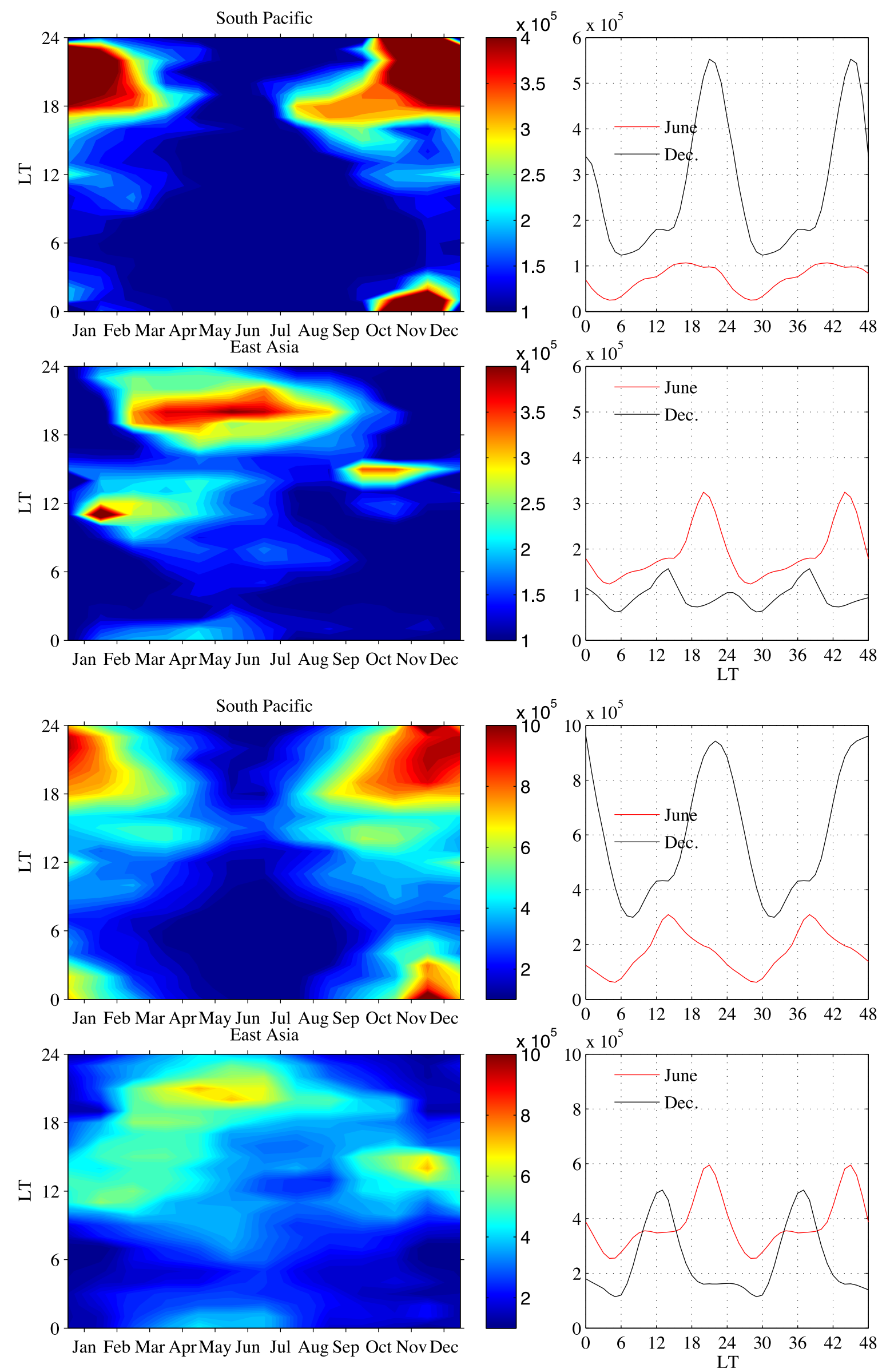

Fig. 2. Month-to-month variation of diurnal cycle of $N_{\mathrm{e}}$ at $400 \mathrm{~km}$ under disturbed conditions in the South Pacific and East Asia region at (Upper) low solar flux levels $\left(F_{10.7} \approx 90\right)$ and (Lower) high solar flux levels $\left(F_{10.7} \approx 160\right)$. 

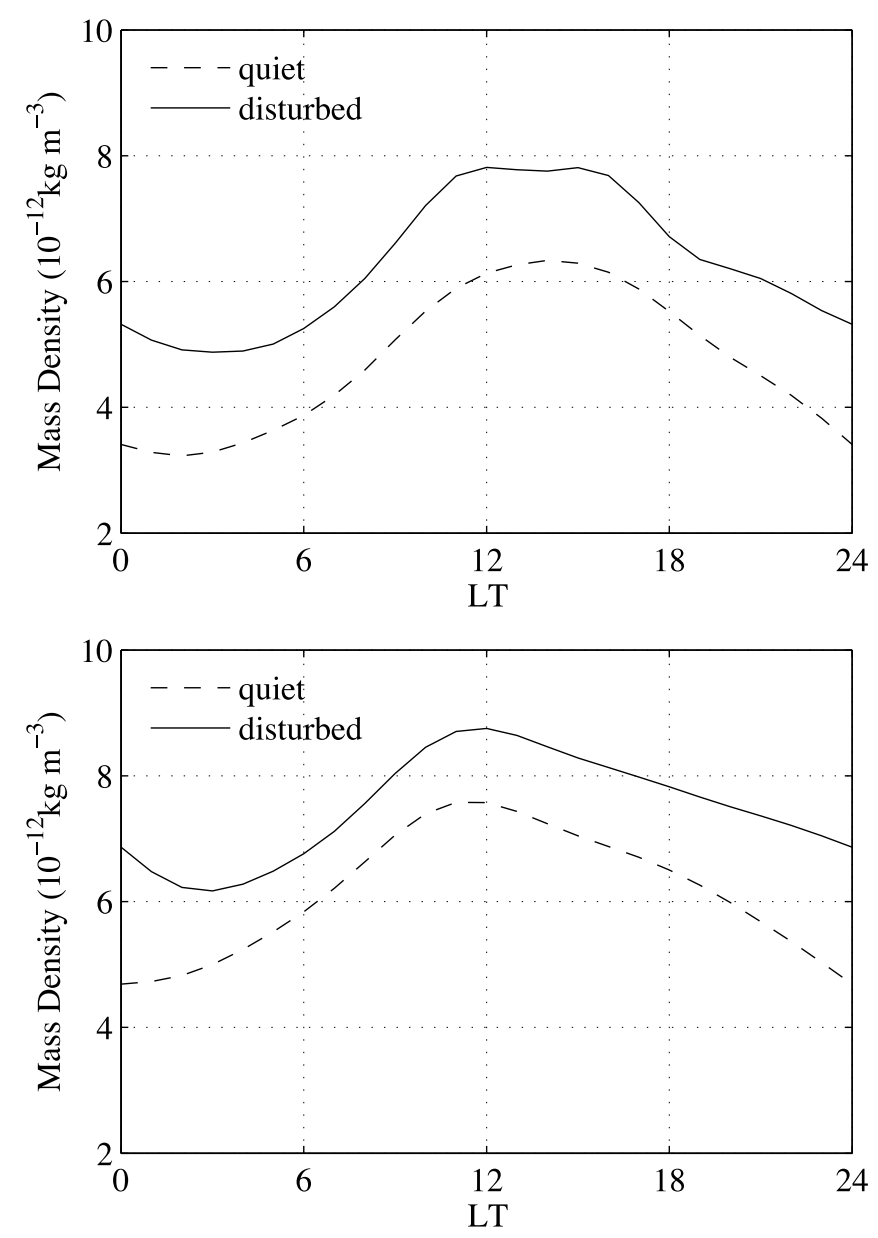

Fig. 3. Diurnal variation of the neutral density at $400 \mathrm{~km}$ in (Upper) EA region and (Lower) SP region at moderate solar flux levels $\left(F_{10.7} \approx 130\right)$.

ing).

\subsection{Month-to-month variation of the diurnal cycle}

The month-to-month variation of the diurnal cycle under disturbed conditions is investigated, taking locations near the center of anomaly regions. Results are shown in Fig. 2 for low and high solar flux levels. In these figures, $N_{\mathrm{e}}$ at $400 \mathrm{~km}$ is presented in the month versus local time frame for SP and EA regions. Line plots for solstices in corresponding regions are also given in the right column.

Compared to those under quiet conditions (figures 2 and 3 in Liu et al. (2010)), the night-time density enhancement tends to occur at earlier local time. For example, in the EA region in July, it occurs around 19-20 LT instead of 21-22 LT under quiet conditions. The density enhancement lasts for shorter period, as indicated by its early disappearance in post-midnight hours. From the line plots in the right columns, the nighttime-to-noontime ratio at summer solstice is estimated to be about 3.1 and 1.8 for SP and EA region at low solar flux level, and 2.1 and 1.7 at high solar flux levels. This is about $30 \%$ lower on average than corresponding values under quiet times. This smaller magnitude is mainly caused by the larger noontime plasma density than the average quiet-time values (this is best seen by comparing the line plots in the right hand-side column in Fig. 2 with that in Liu et al. (2010)).

\section{Discussion}

The above analysis shows a general weakening of the MSNA under disturbed conditions. This is observed in terms of reduced spatial coverage of the anomaly region, smaller magnitude of the reversed diurnal cycle and shorter duration of the nighttime enhancement. These features are likely to be the effect of storm-time equatorward wind and thermospheric composition changes as discussed below.

\subsection{Reduced spatial coverage}

It is known that the storm-induced equatorward wind carries molecular-rich air to night-time midlatitudes, causing both composition and wind disturbance there (Prölss, 1981, 1993; Fuller-Rowell et al., 1994). At $400 \mathrm{~km}$ altitude, the thermosphere total mass density is significantly enhanced by about $20 \%-50 \%$, with stronger effect at night as seen in Fig. 3. This demonstrates the increase of mean molecular mass at a constant altitude, which is a direct effect of increased molecular-rich air. The equatorward wind adds to the night-time background equatorward wind. This further lifts the plasma to higher altitudes with low recombination rate, hence tends to strengthen the MSNA. On the other hand, the molecular-rich air tends to increase the recombination rate and destructs the MSNA. The net result depends on the balance between them. Since the composition disturbance propagates from high to low latitudes with decreasing magnitude, molecular-rich air is more abandant at the poleward edge than at the equatoward edge of MSNA. Thus, 
poleward side of MSNA tends to disappear more easily due to the dominant effect of the composition change, leading to a shrink of the anomaly region and a virtual equatorward shift of the anomaly center as observed.

\subsection{Smaller magnitude}

The thermosphere circulation and composition disturbances mentioned above have a strong local time dependence (Prölss, 1981, 1993). The outflow from the auroral region and molecular enhancement are large at night but small during day. Thus, though the night-time plasma density is significantly reduced by the molecular-rich air, the day-time plasma is less affected by this composition change. On the other hand, the equatorward wind tends to weaken the background daytime poleward wind. As shown in Liu et al. (2010), poleward wind causes depletion of the day-time plasma densities in the anomaly regions. Thus, weakening of the poleward wind would favor a less depleted plasma. This argument is supported by the observations presented here, which show nearly $100 \%$ higher noontime density under disturbed conditions than under quiet conditions (compare the line plots in Fig. 2 with that in Liu et al., 2010). Combined with the less prominent nighttime enhancement, it is natural that the magnitude of the reversed diurnal cycle becomes smaller than that under quiet conditions. The storm-induced equatorward wind can also contribute to the early equatorward turning of the meridional wind in the evening, hence the early occurrence of MSNA in local time.

\subsection{Shorter duration}

Since the molecular enhancement is strongest in postmidnight and morning sector (Prölss, 1993), the MSNA is likely to be significantly weakened or even disappear during these hours as observed. Furthermore, the equatorward wind turns westward due to the Coriolis force. This westward component builds up and can considerably exceeds the equatorward wind at midlatitudes (Richmond and Lu, 2000). This causes a weakening of the nighttime eastward wind, which is projected to the magnetic meridional plane as a decrease of the equatorward wind in sectors with large declination angle, hence lead to a weakening or disappearing of the plasma enhancement in these hours.

\section{Summary}

The geomagnetic storm effects on the MSNA is investigated in this brief report from a statistical point of view. It is found that the anomaly generally becomes weaker under disturbed conditions, with reduced spatial coverage, smaller magnitude of reversed diurnal cycle, and short duration of the nighttime enhancement. These can be reasonably understood by storm-time thermospheric circulation and composition changes. It is noted that, each storm has its particular characteristic, including its start time, duration, strength and time history. The background thermospheric response varies considerably from storm to storm (Liu and Lühr, 2005). Furthermore, significant day-to-day variation exists in MSNA itself (Thampi et al., 2009). Therefore, features shown here are statistical results, and variation during each storm is not necessarily same as presented here.

Acknowledgments. This work is supported by the JSPS research grant.

\section{References}

Balan, N., K. Shiokawa, Y. Otsuka, T. Kikuchi, D. V. Lekshmi, S. Kawamura, M. Yamamoto, and G. J. Bailey, A physical mechanism of positive ionospheric storms at low latitudes and midlatitudes, J. Geophys. Res., 115, A02304, doi:10.1029/2009JA014515, 2010.

Bellchambers, W. H. and W. R. Piggott, Ionospheric measurements made at Halley Bay, Nature, 182, 1596-1597, doi:10.1038/1821596a0, 1958.

Dungey, J. W., Interplanetary magnetic field and the auroral zones, Phys. Rev. Lett., 6, 47-48, doi:10.1103/PhysRevLett.6.47, 1961.

Fuller-Rowell, T. J., M. V. Codrescu, R. J. Moffett, and S. Quegan, Response of the thermosphere and ionosphere to geomagnetic storms, $J$. Geophys. Res., 99, 3893-3914, 1994.

He, M., L. Liu, W. Wan, B. Ning, B. Zhao, J. Wen, X. Yue, and H. Le, A study of the Weddell Sea Anomaly observed by FORMOSAT3/COSMIC, J. Geophys. Res., 114, doi:10.1029/2009JA014175, 2009 (in press).

Horvath, I., A total electron content space weather study of the nighttime Weddell Sea Anomaly of 1996/1997 southern summer with TOPEX/Poseidon radar altimetry, J. Geophys. Res., 111, A12317, doi:10.1029/2006JA011679, 2006.

Horvath, I. and E. A. Essex, The Weddell sea anomaly observed with the TOPEX satellite data, J. Atmos. Sol.-Terr. Phys., 65, 693-706, 2003.

Jee, G., A. G. Burns, Y.-H. Kim, and W. Wang, Seasonal and solar activity variations of the Weddell Sea Anomaly observed in the TOPEX total electron content measurements, J. Geophys. Res., A04307, doi:0.1029/2008JA01380, 2009.

Lin, C. H., J. Y. Liu, C. Z. Cheng, C. H. Chen, C. H. Liu, W. Wang, A. G. Burns, and J. Lei, Three-dimensional ionospheric electron density structure of the Weddell Sea Anomaly, J. Geophys. Res., 114, A02312, doi:10.1029/2008JA013455, 2009.

Liu, H. and H. Lühr, Strong disturbance of the upper thermospheric density due to magnetic storms: CHAMP observations, J. Geophys. Res., 110, A09S29, doi:10.1029/2004JA010908, 2005.

Liu, H., C. Stolle, S. Watanabe, T. Abe, M. Rother, and D. L. Cooke, Evaluation of the IRI model using CHAMP observations in polar and equatorial regions, Adv. Space Res., doi:10.1016/j.asr.2006.08.006, 2007.

Liu, H., S. Thampi, and M. Yamamoto, Phase reversal of the diurnal cycle in the midlatitude ionosphere, J. Geophys. Res., 115, A01305, doi:10.1029/2009ja014689, 2010.

Prölss, G., Latitudinal structure and extension of the polar atmospheric disturbance, J. Geophys. Res., 86, 2385-2396, 1981.

Prölss, G., Common origin of positive ionospheric storms at middle latitudes and the geomagnetic activity effect at low latitudes, J. Geophys. Res., 98, 5981-5991, 1993.

Richmond, A. D. and G. Lu, Upper-atmosheric effects of magnetic storms: a brief tutorial, J. Atmos. Sol.-Terr. Phys., 62, 1115-1127, 2000.

Thampi, S., C. H. Lin, H. Liu, and M. Yamamoto, First Tomographic observations of the mid-latitudes summer night anomaly (MSNA) over Japan, J. Geophys. Res., 114, A10318, doi:10.1029/2009JA014439, 2009.

H. Liu (e-mail: huixin@serc.kyushu-u.ac.jp) and M. Yamamoto 